Research Article

\title{
A comparative study of efficacy of atorvastatin, rosuvastatin, and atorvastatin + fibrates as lipid lowering agents
}

\author{
${\text { Karunasree } \text { Nagarur }^{1}{ }^{*}, \text { Yamini Vadlamannati }^{1} \text {, Narasimha Rao Raja }}^{2}$
}

\begin{abstract}
${ }^{1}$ Department of Pharmacology, Government Medical College, Nizamabad, Telangana, India ${ }^{2}$ Health Director, Central Hospital, S C Railway, Secundrabad, Telangana, India
\end{abstract}

Received: 22 June 2016 Accepted: 05 August 2016

\section{*Correspondence to: \\ Dr. Karunasree Nagarur, Email: raja_narasimharao@ yahoo.com}

Copyright: (c) the author(s), publisher and licensee Medip Academy. This is an open-access article distributed under the terms of the Creative Commons Attribution Non-Commercial License, which permits unrestricted non-commercial use, distribution, and reproduction in any medium, provided the original work is properly cited.

\section{ABSTRACT}

Background: Hypercholesterolemia patients are at high risk of coronary heart disease. National cholesterol education programme (NCEP) Adult Treatment Panel III guidelines provide the option of aggressively lowering Low-density cholesterol in them. Presently the standard therapy of hypercholesterolemia is by $\mathrm{HMG}$ co-A reductase inhibitors. Present study shows that Rosuvastatin is better than Atorvastatin, Atorvastatin and Fibrate is better than Atorvastatin monotherapy in management of hypercholesterolemia.

Methods: The present research was an observational study conducted at Government general hospital, Nizamabad. A total of 150 patients on treatment for hypercholesterolemia for more than one year were enrolled in our study. They were divided into three groups. Group I: Atorvastatin $(20 \mathrm{mg})(\mathrm{n}=96$; 64\%); Group II: Rosuvastatin $10 \mathrm{mg}(\mathrm{n}=41 ; 27.33 \%)$; Group III: Atorvastatin $(20 \mathrm{mg})+$ Fibrate $(145 \mathrm{mg})(\mathrm{n}=13 ; 8.66 \%)$.

Results: Rosuvastatin is better than Atorvastatin and Atorvastatin with fibrates reduces LDL, TG more than Atorvastatin alone.

Conclusions: Rosuvastatin is better than Atorvastatin and Combination of atorvastatin with fibrates reduces LDL-Cholesterol and triglycerides more than atorvastatin alone.

Keywords: Atorvastatin, Rosuvastatin, Atorvastatin + Fibrates, LDL (low density cholesterol), TG (triglycerides), HDL (high density cholesterol), TC (total cholesterol)

\section{INTRODUCTION}

Hypercholestrolemic patients are at a high risk for coronory heart disease. The National Cholesterol Eradication Programme (NCEP) Adult Treatment Panel III (ATP III) guidelines provide the option of aggressively lowering low density lipoprotein cholesterol (LDL-C) in hypercholesterolemia patients. ${ }^{1}$ LDL Cholesterol is associated with an increased risk of atherosclerosis and coronary heart disease. ${ }^{2}$ In contrast, higher levels of HDL Cholesterol are protective. ${ }^{3}$

Presently the standard therapy of hypercholesterolemia is HMG Co A reductase inhibitors. The aim of the present study is to compare the efficacy of Atorvastatin and Rosuvastatin and Atorvastatin monotherapy with combination of Atorvastatin with Fibrate as the lipid lowering agents.

\section{METHODS}

The study was conducted for a period of 18 months during the period of December 2013 to June 2015, on patients suffering from hyperlipidemia attending the medical and surgical OPD's of Government medical college, Nizamabad. The approval of Institutional Ethics committee (IEC) was taken before the start of the study.

Total 150 patients of both sexes, of age between 18-75 years and who were already on treatment for hyperlipidemia for more than 1 year were included in our study. Patients who are using injectable lipid lowering 
drugs and with serious acute conditions were excluded from the study.

After taking written consent form they have been clinically examined the general parameters are noted. Then the laboratory investigations like TC (Total Cholesterol), HDL (High Density Lipoprotein), LDL (Low Density Lipoprotein), TG (Triglycerides) are recorded once during the study.

Data collected on drugs of study of prescribed hypolipidemic agents, Statins, Fibrates, and the combination regimens in subjects who were kept on such drugs. Data at the time of initiation of therapy is recorded and compared the same at the time of observation.

The optimal plasma lipid levels for treatment guidelines as per National Cholesterol Education Programme (2001), Risk of CAD: a) Optimal level -low risk, b) Borderline high-moderate risk, c) High level-high risk. Plasma lipid levels are as shown in Table 1.

The patients were divided into three groups. Group I: Atorvastatin (20 mg) (n=96; 64\%); Group II: Rosuvastatin (10 mg) ( $\mathrm{n}=41 ; 27.33 \%)$; Group III:

Atorvastatin $(20 \mathrm{mg})+$ Fibrates $(145 \mathrm{mg})(\mathrm{n}=13 ; 8.66 \%)$.

\section{Statistical analysis}

Using SPSS software version 16 statistical analysis was done.

The treatment groups were compared for efficacy using Students paired $\mathrm{t}$ Test.

\section{RESULTS}

At the end of the study the following observations and results were obtained:

Table 2 explains that there is a significant reduction in mean value of TC $(22.98 \%, \mathrm{p}<0.0001)$, LDL $(33.8 \%, \mathrm{P}$ $<0.0001)$, TG $(20.14 \%, \mathrm{p}=0.0001)$ and significant increase in HDL $(2.6 \%, \mathrm{p}<0.0001)$ after treatment. There is a significant reduction in mean value of TC $(25.66 \%, \mathrm{P}$ $<0.0001)$, LDL (39.59\%, p <0.0001), TG (31.41\%, P $<0.0001)$, and significant increase in HDL $(12.67 \%, \mathrm{P}$ $<0.0001)$ after treatment.

As given in Table 2, there is a significant reduction in mean value of TC $(22.17 \%, \mathrm{P}=0.0001)$, LDL $(34.66 \%, \mathrm{p}$ $=0.0001)$, $\mathrm{TG}(30.36 \%, \mathrm{P}=0.0001)$, and significant increase in $\mathrm{HDL}(3.05 \%, \mathrm{P}=0.0001)$ after treatment.

Table 1: Plasma lipid levels.

\begin{tabular}{|llll|}
\hline Parameters & Desirable & Borderline & High \\
\hline TC & $<200 \mathrm{mg} / \mathrm{dl}$ & $200-239 \mathrm{mg} / \mathrm{dl}$ & $>240 \mathrm{mg} / \mathrm{dl}$ \\
\hline LDL & $<130 \mathrm{mg} / \mathrm{dl}$ & $130-159 / \mathrm{dl}$ & $>160 \mathrm{mg} / \mathrm{dl}$ \\
\hline TG & $<150 \mathrm{mg} / \mathrm{dl}$ & $150-199 \mathrm{mg} / \mathrm{dl}$ & $>200 \mathrm{mg} / \mathrm{dl}$ \\
\hline HDL & $>40 \mathrm{mg} / \mathrm{dl}$ for men, $>50 \mathrm{mg} / \mathrm{dl}$ for women & - & $>60 \mathrm{mg} / \mathrm{dl}$ \\
\hline
\end{tabular}

Table 2: Lipid profile of Atorvastatin treated cases.

\begin{tabular}{|llllll|}
\hline \multirow{2}{*}{ Parameters } & Group-I (Atorvastatin) & Mean & SEM & P value & \% decrease \\
\cline { 2 - 4 } & Pre Rx & 248.13 & 0.79 & \multirow{2}{*}{0.0001} & 22.98 \\
\hline \multirow{2}{*}{ LDL } & Pre Rx & 191.35 & 0.38 & & \\
\cline { 2 - 4 } & Post Rx & 170.8 & 0.78 & \multirow{2}{*}{0.0001} & 33.8 \\
\hline \multirow{2}{*}{ TG } & Pre Rx & 113 & 0.30 & & 20.14 \\
\cline { 2 - 4 } & Post Rx & 204.11 & 0.90 & \multirow{2}{*}{0.0001} & \\
\hline \multirow{2}{*}{ HDL } & Pre Rx & 163 & 0.76 & & 2.6 \\
\cline { 2 - 4 } & Post Rx & 40.12 & 0.13 & \multirow{2}{*}{0.0001} & \\
\hline
\end{tabular}

Table 3: Lipid profile of Rosuvastatin treated cases.

\begin{tabular}{|llllll|}
\hline Parameters & Group-II (Rosuvastatin) & Mean & SEM & P value & \% decrease \\
\hline \multirow{2}{*}{ TC } & Pre Rx & 272 & 0.77 & \multirow{2}{*}{0.0001} & 25.66 \\
\cline { 2 - 4 } & Post Rx & 202.2 & 0.46 & & \\
\hline \multirow{2}{*}{ LDL } & Pre Rx & 190.7 & 0.82 & \multirow{2}{*}{0.0001} & 39.59 \\
\cline { 2 - 4 } & Post Rx & 115.2 & 0.21 & & \\
\hline \multirow{2}{*}{ TG } & Pre Rx & 233.3 & 1.08 & \multirow{2}{*}{0.0001} & \\
\cline { 2 - 4 } & Post Rx & 160 & 1.35 & & \\
\hline \multirow{2}{*}{ HDL } & Pre Rx & 44.02 & 0.36 & \multirow{2}{*}{0.0001} & 12.67 \\
\cline { 2 - 4 } & Post Rx & 49.6 & 0.34 & & \\
\hline
\end{tabular}


Table 4: Lipid profile of Atorvastatin + Fibrates treated cases.

\begin{tabular}{|c|c|c|c|c|c|}
\hline Parameters & $\begin{array}{l}\text { Group-III } \\
\text { (Atorvastatin+Fibrates) }\end{array}$ & Mean & SEM & $P$ value & $\%$ decrease \\
\hline \multirow{2}{*}{ TC } & Pre Rx & 231.3 & 1.25 & \multirow{2}{*}{0.0001} & \\
\hline & Post Rx & 180 & 0.71 & & 22.17 \\
\hline \multirow[b]{2}{*}{ LDL } & Pre Rx & 150 & 1 & \multirow{2}{*}{0.0001} & \\
\hline & Post Rx & 98 & 0.75 & & 34.66 \\
\hline \multirow{2}{*}{ TG } & Pre Rx & 190 & 1.23 & \multirow{2}{*}{0.0001} & \\
\hline & Post Rx & 132.3 & 1.43 & & 30.36 \\
\hline \multirow{2}{*}{ HDL } & Pre Rx & 42.5 & 0.33 & \multirow{2}{*}{0.0001} & \\
\hline & Post Rx & 43.8 & 0.27 & & 3.05 \\
\hline
\end{tabular}

Table 5: The post treatment values between Group I and II, Group I and III, Group II and III.

\begin{tabular}{|c|c|c|c|c|c|c|c|c|}
\hline & TC & & LDL & & TG & & HDL & \\
\hline Groups & I & II & I & II & I & II & I & II \\
\hline Mean & $\begin{array}{l}191.3 \\
5\end{array}$ & 202.2 & 113 & 115.2 & 163 & 160 & 41.2 & 49.6 \\
\hline SEM & 0.38 & 0.46 & 0.30 & 0.21 & 0.76 & 1.35 & 0.13 & 0.34 \\
\hline$\%$ decrease & 22.98 & 25.66 & 33.8 & 39.59 & 20.14 & 31.41 & 2.6 & 12.67 \\
\hline$P$ value & 0.0001 & & 0.0001 & & 0.3789 & & 0.0001 & \\
\hline Groups & I & III & I & III & I & III & I & III \\
\hline Mean & $\begin{array}{l}191.3 \\
5\end{array}$ & 180 & 113 & 98 & 163 & 132.3 & 41.2 & 43.8 \\
\hline SEM & 0.38 & 0.71 & 0.30 & 0.75 & 0.76 & 1.43 & 0.13 & 0.27 \\
\hline$\%$ decrease & 22.98 & 22.17 & 33.8 & 34.66 & 20.14 & 30.36 & 2.6 & 3.05 \\
\hline$P$ value & 0.0001 & & 0.0001 & & 0.0001 & & 0.0001 & \\
\hline Groups & II & III & II & III & II & III & II & III \\
\hline Mean & 202.2 & 180 & 115.2 & 98 & 160 & 132.3 & 49.6 & 43.8 \\
\hline SEM & 0.46 & 0.71 & 0.21 & 0.75 & 1.35 & 1.43 & 0.34 & 0.27 \\
\hline$\%$ decrease & 25.66 & 22.17 & 39.59 & 34.66 & 31.41 & 30.36 & 12.67 & 3.05 \\
\hline P value & 0.0001 & & 0.0001 & & 0.0001 & & 0.0001 & \\
\hline
\end{tabular}

Table 5 shows the post treatment values TC, LDL, TG, HDL compared in between groups i.e between Group I and Group II, Group I and Group III values, Group II and Group III.

Comparison of changes in lipid profile between Atorvastatin and Rosuvastatin group after treatment showed significant reduction in TC $(22.98 \%$ vs $25.66 \%$, $\mathrm{P}<0.0001)$, LDL $(33.8 \%$ vs $39.59 \%, \mathrm{P}<0.0001)$, increase in HDL which was significant $(2.6 \%$ vs $12.67 \%$ $\mathrm{P}<0.0001)$, but the reduction in TG level was insignificant $(20.14 \%$ vs $31.41 \%, \mathrm{P}<0.3789)$.

Comparison of changes in lipid profile between Atorvastatin and combination of Atorvastatin and Fibrate showed significant reduction in TC $(22.98 \%$ vs $22.17 \%$, $\mathrm{P}<0.0001)$, LDL $(33.8 \%$ vs $34.66 \%, \mathrm{P}<0.0001)$, TG $(20.14 \%$ vs $30.36 \%, P<0.0001)$ and increase in significant increase in level of HDL $(3.05 \%$ vs $0.002 \%, \mathrm{P}$ $<0.0001)$ after treatment.

Comparison of changes in lipid profile between Rosuvastatin and combination of Atorvastatin and Fibrate after treatment showed significant decrease in TC
(25.66\% vs $22.17 \%, \mathrm{P}<0.0001)$, LDL $(39.59 \%$ vs $34.66 \%, \mathrm{P}<0.0001)$, TG (31.41\% vs $30.36 \%, \mathrm{P}<0.0001)$ and significant increase in HDL $(12.67 \%$ vs $3.05 \%, \mathrm{P}$ $<0.0001)$ after treatment.

\section{DISCUSSION}

Table 2 shows the pre-treatment and post treatment values after $20 \mathrm{mg}$ Atorvastatin. This table shows the difference in the lipid profile after treatment with Atorvastatin. There is a significant reduction in mean value of TC $(22.98 \%, \mathrm{P}<0.0001)$, Our study is similar to Meenakshi et al TC $(28 \%, \mathrm{P}<0.001)$, Maruti et al TC $(25.5 \%, \mathrm{P}<0.0001)$, Bener et al $(15.5 \%, \mathrm{P}<0.001){ }^{4-6}$ There was a significant decrease in the mean LDL (pretreatment $=248.13 \mathrm{mg} / \mathrm{dl}$ vs post treatment $=191.35$ $\mathrm{mg} / \mathrm{dl}$; $\mathrm{P}<0.0001)$ with a mean reduction of $33.8 \%$. This finding related to the study conducted by Maruti et al showed 35\%, ( $\mathrm{P}<0.001)$ reduction in LDL after Atorvastatin treatment and Meenakshi et al 37\% (P $<0.001$ ) reduction in LDL. ${ }^{4,5}$

There was a significant decrease in the mean value of TG after Atorvastatin treatment (pre-treatment $=204.11 \mathrm{mg} / \mathrm{dl}$ 
vs post treatment $=163 \mathrm{mg} / \mathrm{dl}, \mathrm{P}<0.0001$ ) with a mean reduction of $20.14 \%$. Our study was similar to Barakat et al TG (19.95\%, P <0.01), Lella et al TG $(20 \%$, P <0.001), Benner et al TG $16.7 \%$ ( $\mathrm{P}<0.01)$, Stalenhoef et al TG $25.2 \%(\mathrm{P}<0.001){ }^{5-8}$

There was significant increase in HDL level in our study (pre-treatment $=40.12 \mathrm{mg} / \mathrm{dl}$, post-treatment $=40.2 \mathrm{mg} / \mathrm{dl}$ ) ( $\mathrm{P}<0.0001)$ with mean reduction in $2.6 \%$. This study correlates with Lella et al HDL $1.5 \%$, Stalenhoef et al HDL 5.8\%, P <0.01, Barakat et al HDL 5.5\%. ${ }^{4,7,8}$

Table 3 shows a significant reduction in mean value of TC (pre-treatment $=272 \mathrm{mg} / \mathrm{dl}$, post treatment $=202.2$ $\mathrm{mg} / \mathrm{dl}, \mathrm{p}=0.0001)$ with a mean reduction of 25.66 with Rosuvastatin. Our study is similar to Bener et al, Barakat et al, and Arshad et al. ${ }^{6,7,9}$

Our study shows significant reduction in LDL in Rosuvatatin treated cases (pre-treatment $=190.7 \mathrm{mg} / \mathrm{dl}$ post treatment $=115.2 \mathrm{mg} / \mathrm{dl}, \mathrm{P}<0.0001)$ with reduction in $39.59 \%$. This is similar to Maruti et al LDL $29.03 \%$ $(\mathrm{P}<0.001)$, Stalenhoef et al LDL $48.5 \%$. $^{5,8}$

In Rosuvastatin treated cases there was significant decrease in TG. (pre-treatment value $=233.3 \mathrm{mg} / \mathrm{dl}$ post treatment value $=160 \mathrm{mg} / \mathrm{dl}, \mathrm{P}<0.0001)$, with mean reduction $31.41 \%$. This correlates with Beneret al TG $25.2 \%(\mathrm{p}<0.001)$ and Barakat et al TG $(25.1, \mathrm{p}<0.01){ }^{6,7}$

Our study showed significant increase in the mean value of HDL (pre-treatment $=44.02 \mathrm{mg} / \mathrm{dl}$, post treatment $=49.6 \mathrm{mg} / \mathrm{dl}, \mathrm{p}<0.0001) 12.67 \%$ after treatment. This is similar to Marutiet al HDL-14\% ( $\mathrm{P}=0.001)$, Stalenhoef et al HDL-10. ${ }^{5,8}$

Table 4 shows the pre-treatment and post-treatment values after Atorvastatin and Fibrate combination. There is a significant reduction in mean value of TC (pretreatment $=231.3$, post treatment $=180, \mathrm{P}<0.0001)$, $22.17 \%$ reduction. This is similar to Lella et al TC $31 \%$, $\mathrm{P}<0.001 .^{4}$

LDL (pre-treatment $=150$, post treatment $=98 \mathrm{P}$ value $0.0001), 34.66 \%$ reduction, this is similar to Lells et $\mathrm{al}^{4}$ LDL 33\% P<0.001. Similarly TG (pre-treatment $=190$, post treatment $=132.3, \mathrm{P}=0.0001) 30.36 \%$, reduction after treatment. This is similar to Lella et al LDL $39 \%, \mathrm{P}$ $<0.001 .^{4}$

There was significant increase in the mean value of HDL (pre-treatment $=190 \mathrm{mg} / \mathrm{dl}$, post treatment $=132.3 \mathrm{mg} / \mathrm{dl}$, $\mathrm{P}<0.0001 ; 3.05 \%$ increase. This is similar to study by Khan HDL $5.18 \%{ }^{10}$ Table 5 shows the post treatment values of lipid profile in between all the 3 groups. There is significant difference $(\mathrm{P}<0.0001)$ in TC, LDL, HDL between group I (Atorvaststin) and group II (Rosuvastatin). But there is insignificant decrease in TG level, $\mathrm{P}<0.3789$ ). There is significant reduction in $\mathrm{TC}$, LDL, TG, HDL between group I and group III after treatment and also between group II and group III. (P $<0.0001)$.

In our study Rosuvastatin is best in decreasing LDL level to $39 \%$. This is similar to Eliasson et al ${ }^{11}$ Rosuvastatin $67 \%$, Clearfield et $\mathrm{al}^{12}$ (Rosuvastatin $10 \mathrm{mg}$ reduced LDL-C levels significantly more than atorvastatin $20 \mathrm{mg}$ at week 6 (44.6\% vs. $42.7 \%, \mathrm{P}<0.05) .^{11,12}$

In our result Atorvastatin with Fibrates was better than Atorvastatin monotherapy in decreasing LDL (34.66\% vs $33.85 \%$ ) our result was similar to the results of Karalis et al $(33 \%$ vs $35 \%){ }^{13}$

Michael et al showed reduction in HDL (40\%) more in Atorvastatin and Fibrate combination than in Atorvastatin monotherapy. ${ }^{12}$ This is similar to our result $(3 \%, \mathrm{P}$ $<0.0001$ ) in lowering HDL in Group I (Atorvatatin) vs Group III (Atorvastatin and Fibrate).

Funding: No funding sources

Conflict of interest: None declared

Ethical approval: The study was approved by the Institutional Ethics Committee

\section{REFERENCES}

1. Hunninghake DB, Ballantyne CM, Maccubbin DL. Comparative effects of simvastatin and atorvastatin in hypercholesterolemic patients with characteristics of metabolic syndrome. Clinical therapeutics 2003;25:1670-86.

2. Carmena R, Duriez P, Fruchart JC. Atherogenic lipoprotein particles in atherosclerosis. Circulation. 2004;109(23):2-7.

3. Kontush A, Chapman MJ. Antiatherogenic small, dense HDL-guardian angel of the arterial wall. Mar2006. Nat Clin Pract Cardiovasc Med. 2006;3(3):144-53.

4. Lella M, Indira K. A comparative study of efficacy of atorvastatin alone and its combination with fenofibrate on lipid profile in type 2 diabetes mellitus patients with hyperlipidemia. J Adv Pharm Technol Res. 201;4(3):166-70.

5. Adsule SM, Baig MS, Gade PR, Khandelwal PN. Comparative evaluation of safety and efficacy of rosuvastatin, simvastatinand atorvastatin in patients of type 2 diabetes mellitus with dyslipidemia.In J Diab Dev Ctries. 2009;29(2):74-9.

6. Bener A, Dogan M, Barakat L, Abdulla OAA AlHamaq. Comparison of efficacy, safety, and cost effectiveness of various statins in dyslipidemic diabetic patients. IJP. 2014;46(1):88-93.

7. Barakat L, Jayyousi M, Bener A, Zuby B, Zirie M. Comparison of Efficacy and Safety of Rosuvastatin, Atorvastatin and Pravastatin among Dyslipidemic Diabetic Patients. ISRN Pharmacol. 2013;2013:1-7.

8. Stalenhoef AFH, Christie M. Ballantyne, Cinzia Sarti3, Jan Murin, Serena Tonstad,Helen Rose, and Wim Wilpshaar. A COmparative study with rosuvastatin in subjects with METabolic Syndrome: 
results of the COMETS study. 2005;26(24):266472.

9. Arshad AR. Comparison of Low-Dose Rosuvastatin with Atorvastatin in Lipid-Lowering Efficacy and Safety in a High-Risk Pakistani Cohort: An OpenLabel Randomized Trial. Journal of Lipids. 2014;2014:1-5.

10. Khan MA, Murti K, Grover V. Atorvastatin vs Rosuvastatin; fenofibrate as an add on: an exploratory study. Int $\mathbf{J}$ of Pharmacy and pharmaceutical. 2014;6(8)493-8.

11. Eliasson B, Svensson A-M, Miftaraj M, Miao Jonasson J.Clinical Use and Effectiveness of Lipid Lowering Therapies in Diabetes Mellitus-An Observational Study from the Swedish National Diabetes Register. Plos one. 2011;6(4):18744.

12. Clearfield MB, Amerena J, Jean-Pierre B. Comparison of the efficacy and safety of rosuvastatin $10 \mathrm{mg}$ and atorvastatin $20 \mathrm{mg}$ in highrisk patients with hypercholesterolemia Prospective study to evaluate the Use of Low doses of the Statins Atorvastatin and Rosuvastatin (PULSAR). Eur Heart J. 2005;26(24):2664-72.

13. Karalis DG, Victor B, Ahedor L, Liu L. Use of Lipid-Lowering Medications and the Likelihood of Achieving Optimal LDL-Cholesterol Goals in Coronary Artery Disease Patients. Cholesterol. 2012;2012:1-7.

Cite this article as: Nagarur K, Vadlamannati Y, Raja NR. A comparative study of efficacy of atorvastatin, rosuvastatin, and atorvastatin + fibrates as lipid lowering agents. Int $\mathbf{J}$ Basic Clin Pharmacol 2016;5:1924-8. 